\title{
Microbial Profile of Fresh Beef Sold in the Markets of Ngaoundéré, Cameroon, and Antiadhesive Activity of a Biosurfactant against Selected Bacterial Pathogens
}

\author{
Hippolyte T. Mouafo ${ }^{(D,},{ }^{1,2}$ Annick M. B. Baomog, ${ }^{1}$ Jorelle J. B. Adjele, ${ }^{1}$ \\ Alphonse T. Sokamte, ${ }^{2}$ Augustin Mbawala, ${ }^{2}$ and Robert Ndjouenkeu $\mathbb{D}^{2}$ \\ ${ }^{1}$ Centre for Food and Nutrition Research, Institute of Medical Research and Medicinal Plants Studies, PO. Box 6163, \\ Yaoundé, Cameroon \\ ${ }^{2}$ Department of Food Sciences and Nutrition, National School of Agroindustrial Sciences, University of Ngaoundéré, PO. Box 454, \\ Ngaoundéré, Cameroon
}

Correspondence should be addressed to Hippolyte T. Mouafo; hippolyte.tene@gmail.com

Received 26 November 2019; Revised 10 January 2020; Accepted 27 January 2020; Published 19 February 2020

Academic Editor: Efstathios Giaouris

Copyright ( $\odot 2020$ Hippolyte T. Mouafo et al. This is an open access article distributed under the Creative Commons Attribution License, which permits unrestricted use, distribution, and reproduction in any medium, provided the original work is properly cited.

\begin{abstract}
Owing to its composition, meat is recognized as one of the best media for microbial growth leading to meat spoilage and foodborne illness. The ability of microorganisms to adhere to surfaces where meat is deposited during selling is a nonnegligible cause of meat contamination. This work was performed to assess the microbial profile of fresh beef sold in the markets of Ngaoundéré town and evaluate the antiadhesive activity of a biosurfactant derived from Lactobacillus paracasei subsp. tolerans N2 against selected pathogenic strains isolated in fresh beef. All fresh beef samples analysed were contaminated with both pathogenic and spoilage microorganisms at levels higher than the microbiological criteria set by the European Commission. A total of 151 strains belonging to 12 species (Pseudomonas putida, Pseudomonas aeruginosa, Pseudomonas sp., Escherichia coli 1, Escherichia coli, Salmonella enteritidis, Salmonella sp., Staphylococcus epidermidis, Staphylococcus xylosus, Staphylococcus aureus, Candida albicans, and Candida sp.) were isolated and identified. A specific relationship between the microbial diversity of fresh beef and the sampling sites was observed. Biosurfactant displayed antiadhesive activity against all the tested strains and the complete inhibition (100\%) of Bacillus sp. BC1, S. aureus STP1, and S. xylosus STP2 was noticed at biosurfactant concentration of $10 \mathrm{mg} / \mathrm{mL}$. This study indicates the microbial diversity of fresh beef sold in Ngaoundéré markets and suggests the potential use of biosurfactant as an antiadhesive agent in the meat industry.
\end{abstract}

\section{Introduction}

Meat is a regular part of the human diet worldwide. It contains proteins (with all essential amino acids), vitamins (A, B12, B6, D, and E), and minerals (iron and zinc) which are very important for human growth and well-being [1]. Due to its nutrient content, meat is a highly perishable food as it represents good media for the proliferation of microorganisms $[1,2]$. These microorganisms are essentially spoilage organisms (Brochothrix thermosphacta, Lactobacillus spp., Clostridium spp., Leuconostoc spp., Carnobacterium spp., Pseudomonas spp. Candida spp.,
Penicillium, Mucor, Aspergillus, Rhyzopus, and Enterobacteriaceae) responsible for off-odors, discoloration, development of slime, and production of toxic compounds and pathogens (Salmonella spp., E. coli, Staphylococcus aureus, Listeria monocytogenes, and Campylobacter spp.) responsible for food-borne diseases [3]. Generally, meat is consumed cooked, but according to some food habits and traditional recipes, meat may be consumed raw or partially cooked [4]. Under these conditions, the consumption of meat was many times associated with outbreaks of foodborne diseases [5]. According to the World Health Organization, $30 \%$ of inhabitants in industrialized countries 
suffer every year of food-borne diseases [6] with most of the cases attributable to the consumption of meat [7]. In sub-Saharan Africa, food-borne diseases due to the consumption of meat are not uncommon. Because of the weakness of bacteriological diagnose resources associated with the unawareness and nonenforcement of laws [8], the estimation of food-borne diseases as well as resulting losses is underevaluated [9].

Nowadays, as the demand and consumption of raw meat have increased in many countries [10], regulations which specified the microbiological criteria of raw meat have been established in order to protect consumers' health and to facilitate its commercialization. To this end, the microbial contamination of meat is becoming a public health concern worldwide and particularly in Cameroon [11]. It has been reported in the literature that microorganisms contaminate meat during the production, processing, transportation, and distribution processes [12]. The first step in the control of the microbiological quality of meat consists of evaluating their initial contamination levels and identifying the different microorganisms involved. The studies assessing the microbiological quality of fresh beef have been carried out in several countries such as Turkey [13], Ethiopia [1], Nigeria [14], Sudan [15], Ghana [16], Rwanda [17], and India [18]. It therefore appears interesting to perform such kind of study in some Cameroonian metropolises where fresh beef is highly consumed by the whole class of the population.

Another important step in the control of the microbiological quality of meat is the cleaning process of surfaces where meat is processed [19]. A study conducted by Zerabruk et al. [1] showed the presence at high levels of different groups of microorganisms on cutting tables in butcher shops of Addis Ababa. In fact, microorganisms display the ability of adhering to the surface and forming structured communities encapsulated within a self-developed polymeric matrix known as biofilms which are resistant to the conventional cleaning processes. Therefore, inhibiting the initial adhesion of microorganisms to surfaces is a challenging task in the meat industry. Utilization of biosurfactants which deserve antiadhesive properties [20-22] appears as an alternative. Biosurfactants are amphiphilic compounds produced by a wide variety of microorganisms such as bacteria, yeasts, and moulds that can have some influence on interfaces. Opposite to their synthetic homologues, these compounds have unique characteristics such as being nontoxic, biodegradable, environmentally friendly, and selective, having structural diversity, being effective under extreme conditions of $\mathrm{pH}$, temperature, and salinity, and having unique surface-active properties [23]. To the limit of our knowledge, the antiadhesive properties of biosurfactants were not yet tested against strains isolated from fresh beef despite the ability of these strains of adhering to cutting meat surfaces. Hence, the objective of the present work is to establish the microbial profile of fresh beef sold in Ngaoundéré, Cameroon, and evaluate the antiadhesive properties of biosurfactants against selected pathogenic strains isolated in fresh beef.

\section{Materials and Methods}

2.1. Study Area. The study was conducted in the city of Ngaoundéré, Adamawa region of Cameroon, from February 2015 to May 2016. The six main markets of the town where fresh beef is daily sold were chosen. These markets were Bantail market (MBT), Bamnyanga market (MBG), Dang market (MD), "Grand Marché" (GM), "Petit Marché" (PM), and "Centre Commercial" (CC).

2.2. Fresh Beef Samples. The normalized method ISO 17604: 2015 [24] which specifies the sampling methods for the detection and enumeration of microorganisms on the surface of carcasses or part of carcasses of slaughtered meat was used for the sampling procedure. 10 samples of $500 \mathrm{~g}$ each were collected in the morning (between 9:30 and 10:30 AM) from butcher shops in each market using a systematic random sampling technique. Briefly, in each market, butcher shops were numbered and the corresponding number was noted on a paper. The papers bearing each number were folded, introduced into a closed container, and thoroughly mixed. One paper was selected from the container and its number was recorded. The paper was reintroduced into the container and the container was thoroughly mixed again. In the case that the same number was drawn twice, the second drawing was not considered and the number was returned to the container. The operation was performed until 10 butcher shops were selected. The collected samples were transferred into a sterile bag. After being labelled, the samples were stored in an icebox and transported to the lab for analyses.

2.3. Biosurfactant. The biosurfactant used in this study was previously produced by Lactobacillus paracasei subsp. tolerans N2 with sugar cane molasses as substrate and characterized [25]. Biosurfactant was dissolved in methanol and centrifuged at $15000 \mathrm{~g}, 4^{\circ} \mathrm{C}$ for $10 \mathrm{~min}$. The supernatant was filtered $(0.22 \mu \mathrm{m})$ and evaporated to dryness under nitrogen.

2.4. Chemicals. Glacial acetic acid, ethanol, and methanol of HPLC-grade were purchased from Sigma-Aldrich Co., Germany. Plate Count Agar (PCA), Eosin Methylene Bleu (EMB) agar, Bile Azide Esculin (BEA) agar, Mannitol Salt Agar (MSA), Mossel agar, Cetrimide agar and Sabouraud agar supplemented with chloramphenicol, Tryptone Sulfite Neomycin (TSN) agar, Salmonella and Shigella (SS) agar, Selenite cystine broth, Xylose Lysine Decarboxylate (XLD) agar, Triple Iron Sugar (TSI) agar, Brain Heart Infusion (BHI) broth, and Nutrient Agar (NA) were purchased from Scharlau (Germany). All other reagents used in this study were of analytical grade.

2.5. Cultures. The following reference cultures: E. coli MTCC 118, Staphylococcus aureus MTCC 1430, Micrococcus luteus MTCC 106, and Listeria monocytogenes MTCC 839 were used for the antiadhesive test. These Microbial Type Culture Collection (MTCC) strains were kindly provided by the Department of Microbiology and Fermentation 
Technology, CSIR-Central Food Technological Research Institute, Mysore, India.

\subsection{Microbiological Analysis of Fresh Beef Samples}

2.6.1. Sample Preparation. Samples were processed according to the method ISO 6887-2:2017 [26]. In the procedure, $500 \mathrm{~g}$ of the different samples was weighed and ground and $25 \mathrm{~g}$ was introduced into an Erlenmeyer containing $225 \mathrm{~mL}$ of sterile peptone water. The mixture was homogenized for 2 min with a vortex (IKA, Vortex Genius 3, $\mathrm{UK}$ ) and allowed to stand for $30 \mathrm{~min}$ at room temperature. Serial decimal dilutions $\left(10^{-1}\right.$ to $\left.10^{-6}\right)$ were prepared.

2.6.2. Inoculation and Culture Conditions. The total mesophilic aerobic count was determined using the pour plate method [27]. Briefly, $1 \mathrm{~mL}$ of each dilution was introduced into a sterile Petri dish followed with the addition of $20 \mathrm{~mL}$ of sterile PCA. The plates were incubated at $37^{\circ} \mathrm{C}$ for $48 \mathrm{~h}$. Spread plate method was used for the enumeration of total and faecal coliforms [28], faecal Streptococci [29], Staphylococcus spp. [30], Bacillus spp. [31], Pseudomonas spp. [32], yeasts, and moulds [33]. In the procedure, $0.1 \mathrm{~mL}$ of the different dilutions was surface-inoculated on Petri plates containing EMB agar, BEA agar, MSA agar, Mossel agar, Cetrimide agar, and Sabouraud agar supplemented with chloramphenicol, respectively, for total and faecal coliforms, faecal Streptococci, Staphylococcus spp., Bacillus spp., Pseudomonas spp., and yeasts, and moulds. The plates were incubated at $37^{\circ} \mathrm{C}$ for $48 \mathrm{~h}$ for total coliforms, faecal Streptococci, Staphylococcus spp., Bacillus spp., and Pseudomonas spp., at $44^{\circ} \mathrm{C}$ for $48 \mathrm{~h}$ for faecal coliforms, and at $25^{\circ} \mathrm{C}$ for $3-5$ days for yeasts and moulds.

The presence of Salmonella spp. in samples was assessed according to the method ISO 6579-1:2017 [34]. After homogenization of $25 \mathrm{~g}$ of sample in $225 \mathrm{~mL}$ of sterile peptone water, the suspension was incubated for $16 \mathrm{~h}$ at $37^{\circ} \mathrm{C}$ for preenrichment. Then, $1 \mathrm{~mL}$ of the suspension was transferred into a tube containing $10 \mathrm{~mL}$ of sterile selenite cystine broth and incubated for $24 \mathrm{~h}$ at $37^{\circ} \mathrm{C}$ for enrichment. Thereafter, one loopful of each enrichment broth was streaked onto SS and $\mathrm{XLD}$ agar and incubated at $37^{\circ} \mathrm{C}$ for $24 \mathrm{~h}$. Uncolored colonies with black centers on SS agar and red colonies with black centers on XLD agar were considered as Salmonella.

The enumeration of sulphite-reducing Clostridium was done according to the method ISO 7937:2004 [35]. $2 \mathrm{~mL}$ of dilution $\left(10^{-2}\right)$ was introduced into a tube containing $15 \mathrm{~mL}$ of sterile TSN agar, homogenized, and heated at $80^{\circ} \mathrm{C}$ for $10 \mathrm{~min}$. Then, the tubes were rapidly cooled and $1 \mathrm{~mL}$ of sterile paraffin oil was introduced into each tube followed with incubation at $37^{\circ} \mathrm{C}$ for $48 \mathrm{~h}$. After incubation, black colonies were considered as sulphite-reducing Clostridium.

2.6.3. Plates Reading. The colony-forming units (CFU) appearing on the Petri dishes after the incubation period were counted. Only plates with colony-forming units between 30 and 300 were considered. All experiments were performed with three replications and the results were expressed as colony-forming units per gram of fresh beef $(\mathrm{CFU} / \mathrm{g})$.

2.7. Identification of Microorganisms Isolated from Fresh Beef Samples. From each Petri plate, individual colonies were streaked twice on nutrient agar and characterized through macroscopic (colony shape and color), microscopic (Gram staining), cultural (growth at different temperatures and $\mathrm{NaCl}$ concentrations), and standard biochemical tests (catalase, motility, coagulase, oxidase, urease, citrate utilization, indole, gelatin hydrolysis, and TSI test) according to Bergey's Manual of Determinative Bacteriology [36]. Further characterization of the isolates was performed through their Analytical Profile Index (API). The following galleries were used according to the manufacturer's instructions: API $20 \mathrm{E}$, API 20 non-E, API 20 Strep, API 20 Staph, and API 20 AUX (BioMérieux SA, France). The specificity of these galleries was at least $92 \%$. The results were recorded and the identification process was performed with Apident 2.0 (BioMérieux, France). Identity of isolates was confirmed using online API web services (https://apiweb.biomerieux.com) and Bergey's Manual of Determinative Bacteriology for comparison of fermentation profiles.

2.8. Antiadhesive Activity of Biosurfactants. The antiadhesive activity of biosurfactant was assessed against reference cultures and selected cultures isolated from fresh beef following the method of Gudiña et al. [37] with slight modifications. In the procedure, the different strains were cultured in $\mathrm{BHI}$ broth for $16 \mathrm{~h}$ at $37^{\circ} \mathrm{C}$. The culture was centrifuged $(10000 \mathrm{~g}, 10 \mathrm{~min}$, $4^{\circ} \mathrm{C}$ ) and cells were washed three times with phosphatebuffered saline (PBS, pH 7.2). Cells were suspended in PBS and their concentrations were adjusted to $10^{8} \mathrm{CFU} / \mathrm{mL}$. Solutions of biosurfactant at concentrations ranging from 0.01 to $10 \mathrm{mg} /$ $\mathrm{mL}$ were prepared in millipore water. For the test, $200 \mu \mathrm{L}$ of each solution of biosurfactant was introduced into the wells of a sterile 96-well flat-bottomed plastic tissue culture plate (Tarsons, India) and the plates were incubated for $1 \mathrm{~h}$ at $4^{\circ} \mathrm{C}$. Afterwards, the plates were washed twice with PBS and $200 \mu \mathrm{L}$ of the bacterial suspension was added to each well followed with incubation at $4^{\circ} \mathrm{C}$ for $24 \mathrm{~h}$. Then, the plates were washed twice with PBS and adherent cells were fixed with $200 \mu \mathrm{L}$ of methanol 99\%. After incubation at room temperature for $15 \mathrm{~min}$, methanol was removed and plates were air-dried. Adherent cells were stained for 5 min with $200 \mu \mathrm{L}$ of $33 \%$ crystal violet. The plates were washed three times with PBS and air-dried and $200 \mu \mathrm{L}$ of $33 \%(\mathrm{v} / \mathrm{v})$ glacial acetic acid was introduced in each well to resolubilize adherent cells. The optical density of the plates was read at $595 \mathrm{~nm}$ using a Spark ${ }^{\circledR} 10 \mathrm{M}$ Multimode Microplate Reader (Tecan, Switzerland). Wells filled with PBS without biosurfactants were used as control. The inhibition of microbial adhesion was calculated using

$$
\text { Microbial inhibition }(\%)=\left(\frac{A_{0}-A_{i}}{A_{0}}\right) \times 100 \text {, }
$$


where $A_{0}$ is the absorbance of the control and $A_{i}$ is the absorbance of the sample at biosurfactant concentration $i$. For each tested microorganism and biosurfactant concentration, essays were performed in triplicate.

2.9. Statistical Analysis. All experiments were carried out in triplicate. Microbial loads were transformed into logarithms and expressed as means \pm standard deviation. Duncan's Multiple Range test was performed to compare microbial loads of samples with the microbiological criteria of the European Commission [38] and to compare the antiadhesive activity of biosurfactant against the tested microorganisms. The statistical significance was set at $p<0.05$ and Statgraphics centurion XVI version 16.1.18 (StatPoint Technologies, Inc., USA) was used to perform these analyses. Principal component analysis was done with XLSTAT 2018 (Addinsoft, Inc., New York, USA) in order to visualize the association between the microbial strains identified and the sampling sites.

\section{Results and Discussion}

3.1. Microbiological Contamination of Samples. Total aerobic count shows the wide variability of microorganisms which can be found in a product. As observed in Table 1, the total aerobic count of fresh beef samples ranges significantly $(p<0.05)$ from $5.38 \pm 0.01(\mathrm{GM})$ to $5.93 \pm 0.022 \mathrm{Log} \mathrm{CFU} / \mathrm{g}$ (PM). The high level of contamination of fresh beef samples was also reported by Obeng et al. [39] and Goja et al. [15] in their studies. They, respectively, found a total aerobic count ranging from 4.82 to $6.92 \mathrm{Log} \mathrm{CFU} / \mathrm{g}$ of fresh beef sold in Ghanaian markets and from 4.67 to $5.53 \mathrm{Log}$ CFU/g of fresh beef sold in Sudanese markets. Zerabruk et al. [1] notified in their study a total aerobic count of fresh beef sold in butcher shops of Addis Ababa, Ethiopia, which ranged from 5 to $7.12 \mathrm{Log} \mathrm{CFU} / g$. Compared to the microbiological criteria [38], all samples analysed in this study presented a total aerobic count lower than the recommended values (7 Log CFU/g). However, it does not mean that there is no pathogen because it is not necessary to have a high concentration of the total aerobic flora to have safety issues. According to Emele et al. [40], the total aerobic count of a food product does not necessarily determine its sanitary quality; rather it is the range of its different group of microorganisms which determined if the product is safe or not. The safety criteria of fresh beef placed on the market during their shelf life deal with the presence of Salmonella in the samples analysed [38]. Another important criterion for fresh beef placed on the market during their shelf life is the process hygiene criteria. It concerns the presence of microorganisms like Enterobacteria and E. coli in the samples analysed [38]. In this light, pathogenic microorganisms were sought.

Faecal Streptococci, which are indicative of faecal contamination, were found in all samples at loads ranging from $4.33 \pm 0.02(\mathrm{PM})$ to $5.11 \pm 0.14 \mathrm{Log} \mathrm{CFU} / \mathrm{g}(\mathrm{MBT})$. The coliforms, another pathogenic group of microorganisms whose presence in raw meat is indicative of faecal contamination, were assessed. The results (as shown in Table 1) show that total and faecal coliforms were present in the fresh beef samples at loads higher than the values specified by the microbiological criteria (3 and 2.7 Log CFU/g, resp.) of the European Commission [38]. The highest level of contamination was observed at the site CC for both total $(5.93 \pm 0.04 \mathrm{Log} C F U / g)$ and faecal $(5.38 \pm 0.01 \mathrm{Log} C F U / g)$ coliforms. The presence of coliforms in the fresh beef samples could result from the nonrespect of good slaughtering and evisceration practices. The unwholesome cleaning process of equipment and cutting meat surfaces could also explain the high contamination. Moreover, the presence of these Enterobacteria in fresh beef samples could originate from the deplorable levels of hygiene and sanitary practices of butchers as observed during this study. The nonrespect of hygiene during the production, distribution, and selling of meat was notified in the literature as the source of coliforms' contamination [39]. Afnabi et al. [19] have justified the presence of coliforms in beef sold in Northern Cameroon by the poor application of the principles of cleaning and disinfection and the lack of supervision of staff on hygiene.

According to safety criteria of the European Commission Regulation [38], Salmonella must be absent in $25 \mathrm{~g}$ of fresh beef intended to human consumption. However, Salmonella spp. were present in all samples analysed probably as the result of improper sanitary practices of butchers. Hence, the meat was consequently unsafe for consumption. Staphylococci, the germs which indicate the level of hygiene of fresh beef handlers, were found in all samples at loads which significantly $(p<0.05)$ vary from one site to another. The high level of Staphylococcus spp. was observed in the site MD $(4.97 \pm 0.03 \mathrm{Log} C F U / g)$ while the least level was noticed in the site MBT $(4.30 \pm 0.13 \mathrm{Log}$ CFU/ g). Poor hygienic practices of meat handlers during slaughtering, evisceration, cutting, and selling (such as coughing and sneezing) could explain the presence of Staphylococcus spp. in the analysed samples at level higher than the $3 \mathrm{Log} \mathrm{CFU} / \mathrm{g}$ recommended by the European Commission Regulation [38]. A high contamination level $(4.57 \pm 0.87 \mathrm{Log} C F U / g)$ of fresh beef sold in butcher shops of Addis Ababa, Ethiopia, was also noticed by Zerabruk et al. [1].

However, despite the poor sanitary quality of fresh beef observed in this study, sulphite-reducing Clostridium was not found in any sample. This result was very surprising considering the fact that slaughtering, evisceration, dressing, and cleaning of the carcasses are carried out on the ground. Regarding Pseudomonas spp., they were present in all samples at loads which significantly $(p<0.05)$ vary from $4.75 \pm 0.06$ (CC) to $5.05 \pm 0.03 \mathrm{Log} \mathrm{CFU} / \mathrm{g}$ (MD). Their presence in the fresh beef samples is indicative of a high risk of spoilage. In fact, bacteria belonging to Pseudomonas genus are generally recognized to actively contribute to fresh meat spoilage owing to their ability to degrade sugars, lipids, and proteins even at refrigeration temperature [3, 41]. As observed in Table 1, Bacillus spp. were found in all samples with a contamination level which significantly varies from one site to another. The high contamination level was observed in the site MBT $(5.43 \pm 0.07 \mathrm{Log} \mathrm{CFU} / \mathrm{g})$. Yeasts and moulds were enumerated in the different samples and results 
TABLe 1: Mean microbial loads in Log CFU/g of fresh beef samples collected from different markets of the city of Ngaoundéré.

\begin{tabular}{|c|c|c|c|c|c|c|c|}
\hline Microbial types & $\mathrm{PM}(n=10)$ & $\mathrm{GM}(n=10)$ & $\operatorname{MBT}(n=10)$ & MBG $(n=10)$ & $\operatorname{MD}(n=10)$ & $\mathrm{CC}(n=10)$ & Norms \\
\hline Total aerobic count & $5.93 \pm 0.02^{\mathrm{d}}$ & $5.38 \pm 0.01^{\mathrm{a}}$ & $5.82 \pm 0.06^{\mathrm{c}}$ & $5.84 \pm 0.01^{c}$ & $5.51 \pm 0.12^{\mathrm{b}}$ & $5.80 \pm 0.13^{\mathrm{cd}}$ & 7.00 \\
\hline Total coliforms & $5.81 \pm 0.01^{\mathrm{d}}$ & $5.26 \pm 0.08^{\mathrm{b}}$ & $5.02 \pm 0.02^{\mathrm{a}}$ & $5.63 \pm 0.05^{\mathrm{c}}$ & $5.29 \pm 0.01^{\mathrm{b}}$ & $5.93 \pm 0.04^{\mathrm{e}}$ & 3.00 \\
\hline Faecal coliforms & $5.20 \pm 0.01^{\mathrm{d}}$ & $5.08 \pm 0.02^{\mathrm{b}}$ & $4.95 \pm 0.03^{\mathrm{a}}$ & $5.08 \pm 0.11^{\mathrm{abc}}$ & $5.19 \pm 0.01^{c}$ & $5.38 \pm 0.01^{\mathrm{e}}$ & 2.70 \\
\hline Faecal Streptococci & $4.33 \pm 0.02^{\mathrm{a}}$ & $4.65 \pm 0.07^{\mathrm{b}}$ & $5.11 \pm 0.14^{\mathrm{c}}$ & $4.70 \pm 0.12^{\mathrm{b}}$ & $4.39 \pm 0.08^{\mathrm{a}}$ & $4.76 \pm 0.14^{\mathrm{b}}$ & - \\
\hline Staphylococcus spp. & $4.65 \pm 0.02^{\mathrm{b}}$ & $4.35 \pm 0.06^{\mathrm{a}}$ & $4.30 \pm 0.13^{\mathrm{a}}$ & $4.82 \pm 0.11^{\mathrm{cd}}$ & $4.97 \pm 0.03^{\mathrm{d}}$ & $4.87 \pm 0.03^{c}$ & 3.00 \\
\hline Salmonella spp. & + & + & + & + & + & + & 0 \\
\hline SR-Clostridium & - & - & - & - & - & - & 0 \\
\hline Bacillus spp. & $5.36 \pm 0.09^{\mathrm{d}}$ & $5.26 \pm 0.05^{\mathrm{c}}$ & $5.43 \pm 0.07^{\mathrm{e}}$ & $5.09 \pm 0.01^{b}$ & $5.29 \pm 0.02^{\mathrm{c}}$ & $4.48 \pm 0.02^{\mathrm{a}}$ & - \\
\hline Pseudomonas spp. & $4.81 \pm 0.02^{\mathrm{a}}$ & $4.93 \pm 0.06^{\mathrm{c}}$ & $4.82 \pm 0.10^{\mathrm{abc}}$ & $4.87 \pm 0.03^{\mathrm{b}}$ & $5.05 \pm 0.03^{\mathrm{d}}$ & $4.75 \pm 0.06^{\mathrm{a}}$ & 2.00 \\
\hline Yeasts & $4.31 \pm 0.01^{\mathrm{c}}$ & $4.05 \pm 0.02^{\mathrm{a}}$ & $4.20 \pm 0.10^{\mathrm{bc}}$ & $4.26 \pm 0.04^{\mathrm{b}}$ & $4.44 \pm 0.02^{\mathrm{d}}$ & $4.67 \pm 0.11^{\mathrm{e}}$ & - \\
\hline Moulds & $1.76 \pm 0.01^{\mathrm{d}}$ & $1.46 \pm 0.05^{\mathrm{a}}$ & $1.57 \pm 0.03^{\mathrm{b}}$ & $1.63 \pm 0.01^{\mathrm{c}}$ & $2.29 \pm 0.08^{\mathrm{f}}$ & $1.83 \pm 0.02^{\mathrm{e}}$ & - \\
\hline
\end{tabular}

$n=$ number of samples per site; - = absence; += presence; PM = "Petit Marché"; GM = "Grand Marché"; MD = "Dang market"; CC = "Centre Commercial"; MBG = "Bamnyanga market"; MBT = "Bantail market"; SR-Clostridium = sulphite-reducing Clostridium; values with different letters within a line are significantly different $(p<0.05)$ according to Duncan' multiple range test; norms = microbiological criteria of fresh beef established by the European Commission Regulation (EC, 2005).

obtained show that yeasts were present in these samples with loads which range from $4.05 \pm 0.02$ (GM) to $4.67 \pm 0.11 \mathrm{Log} \mathrm{CFU} / \mathrm{g}$ (CC). Moulds' count varies from $1.46 \pm 0.05$ (GM) to $2.29 \pm 0.08 \mathrm{Log} \mathrm{CFU} / \mathrm{g}$ (MD). The presence of these microorganisms in fresh beef samples could result from the contamination during slaughtering, dressing, and evisceration processes. Moreover, air exposition of meat during selling could lead to meat contamination by mould spores.

3.2. Identification of Microorganisms Isolated from Fresh Beef Samples. The strains isolated from the different fresh beef samples were purified and identified by their macroscopic, microscopic, cultural, and biochemical properties. The results obtained show that all the 151 strains isolated belonged to five genera: Pseudomonas, Staphylococcus, Salmonella, Escherichia, and Candida. These isolates were identified at species level using API galleries. Table 2 presents the identification percentages gathered from the fermentative profile of the different isolates on API $20 \mathrm{E}$, API $20 \mathrm{NE}$, API 20 Staph, and API 20 AUX, respectively. Twelve species (12) were identified with at least $97 \%$ of identity as follows: Pseudomonas putida (12 strains), Pseudomonas aeruginosa (13 strains), Pseudomonas sp. (26 strains), Escherichia coli 1 (5 strains), Escherichia coli (14 strains), Salmonella enteritidis (9 strains), Salmonella sp. (15 strains), Staphylococcus epidermidis (8 strains), Staphylococcus xylosus (12 strains), Staphylococcus aureus (18 strains), Candida albicans (5 strains), and Candida sp. (14 strains).

The different isolates identified in this study were grouped by genus, species, and sampling sites (Table 2). The highest microbial diversity (10 species) was observed in the sampling sites $\mathrm{PM}$ and $\mathrm{MBG}$ while the lowest diversity was noticed in the site GM (6 species). Accordingly, the high proportion of strains (20.52\% and 25.82\%) was isolated from fresh beef sold in the sites MBG and PM, respectively. 15.23, 12.58, 17.88, and $7.94 \%$ of strains were, respectively, obtained from fresh beef sold in the sites CC, MD, MBT, and GM.

For the genus Pseudomonas, 51 strains belonging to three species: P. putida (12), P. aeruginosa (13), and Pseudomonas sp. (26) were isolated (Table 2). The proportion of strains isolated varies with the species identified and the sampling sites. The high proportions of P. putida (33.33\%) and Pseudomonas sp. (23.07\%) were noticed in the site CC, and that of $P$. aeruginosa (38.46\%) was observed in the site MBG. The high proportions of strains belonging to the genus Pseudomonas observed in this study (33.77\%) could be justified by the fact that they are versatile bacterium ubiquitous in nature and are mostly found in water and soils. During slaughtering, evisceration, and dressing processing which are generally carried out on the ground, they could easily contaminate the meat. Strains of Pseudomonas sp. and $P$. aeruginosa were also identified in fresh beef sold in Calabar metropolis, Nigeria [14], and in Kenyan markets [42].

The second most important proportion of strains isolated in this study was those belonging to the genus Staphylococcus (25.16\%). A total of 38 strains regrouped in 3 species: S. xylosus (12), S. epidermidis (8), and S. aureus (18) were isolated (Table 2). The high proportion of $S$. aureus $(27.77 \%)$ and S. epidermidis (50\%) was isolated from the site MBT while S. xylosus was isolated only in the sites MBG (66.66\%) and PM (33.33\%). It is important to highlight that the strain S. xylosus is useful in meat processing products as sausage due to its ability to degrade biogenic amines. $S$. aureus considered to be a well-known pathogen to humans was the predominant strain of the genus Staphylococcus with $47.36 \%$. Its predominance could result from contamination through skin, mouth, hand, and noses of butchers as this strain colonized at 40 to $60 \%$ the nasal mucosa and skin of healthy human being. S. xylosus, S. epidermidis, and S. aureus were isolated by Goja et al. [15] in fresh beef sold in markets of Khartoum, Omdurman, and Bahri cities, Sudan.

In this study, 19 strains of $E$. coli belonging to the species E. coli (14) and E. coli 1 (5) were isolated (Table 2). The highest proportion of E. coli strains (28.57\%) was observed in the sites CC, MBG, and PM. Strains of E. coli 1 were noticed only in the sites MD (40\%) and MBT (60\%). The results obtained in the present study corroborate with those mentioned by Balcha et al. [43] who found, on fresh beef sold in Mekelle, Quiha, and Wukro markets of Ethiopia, strains 
TABle 2: Genus, species, identification percentages, and proportions of strains isolated from fresh beef samples collected from different markets of the city of Ngaoundéré.

\begin{tabular}{|c|c|c|c|c|c|c|c|c|c|}
\hline \multirow{2}{*}{ Genus } & \multirow{2}{*}{ Species } & \multirow{2}{*}{$\begin{array}{c}\text { ID percentages } \\
(\%)\end{array}$} & \multirow{2}{*}{$\begin{array}{c}\text { Number of } \\
\text { strains }\end{array}$} & \multicolumn{6}{|c|}{ Numbers and proportions of strains per sampling sites } \\
\hline & & & & $\mathrm{CC}$ & MD & MBG & MBT & GM & PM \\
\hline \multirow{3}{*}{ Pseudomonas } & $\begin{array}{l}\text { Pseudomonas } \\
\text { putida }\end{array}$ & 98.50 & 12 & $\begin{array}{c}4 \\
(33.33 \%)\end{array}$ & $\begin{array}{c}2 \\
(33.33 \%)\end{array}$ & $\begin{array}{c}4 \\
(16.66 \%)\end{array}$ & $\begin{array}{c}0 \\
(0 \%)\end{array}$ & $\begin{array}{c}0 \\
(0 \%)\end{array}$ & $\begin{array}{c}2 \\
(16.66 \%)\end{array}$ \\
\hline & $\begin{array}{l}\text { Pseudomonas } \\
\text { aeruginosa }\end{array}$ & 99.80 & 13 & $\begin{array}{c}2 \\
(15.38 \%)\end{array}$ & $\begin{array}{c}3 \\
(23.07 \%)\end{array}$ & $\begin{array}{c}5 \\
(38.46 \%)\end{array}$ & $\begin{array}{c}0 \\
(0 \%)\end{array}$ & $1(7.69 \%)$ & $\begin{array}{c}2 \\
(15.38 \%)\end{array}$ \\
\hline & Pseudomonas sp. & 97.40 & 26 & $\begin{array}{c}6 \\
(23.07 \%)\end{array}$ & $\begin{array}{c}3 \\
(11.53 \%)\end{array}$ & $\begin{array}{c}3 \\
(11.53 \%)\end{array}$ & $\begin{array}{c}8 \\
(30.76 \%)\end{array}$ & $2(7.69 \%)$ & $\begin{array}{c}4 \\
(15.38 \%)\end{array}$ \\
\hline \multirow[b]{2}{*}{ Escherichia } & Escherichia coli & 99.60 & 14 & $\begin{array}{c}4 \\
(28.57 \%)\end{array}$ & $\begin{array}{c}0 \\
(0 \%)\end{array}$ & $\begin{array}{c}4 \\
(28.57 \%)\end{array}$ & $\begin{array}{c}0 \\
(0 \%)\end{array}$ & $\begin{array}{c}2 \\
(14.28 \%)\end{array}$ & $\begin{array}{c}4 \\
(28.57 \%)\end{array}$ \\
\hline & Escherichia coli 1 & 99.40 & 5 & $\begin{array}{c}0 \\
(0 \%) \\
\end{array}$ & $\begin{array}{c}2 \\
(40.00 \%) \\
\end{array}$ & $\begin{array}{c}0 \\
(0 \%) \\
\end{array}$ & $\begin{array}{c}3 \\
(60.00 \%) \\
\end{array}$ & $\begin{array}{c}0 \\
(0 \%) \\
\end{array}$ & $\begin{array}{c}0 \\
(0 \%) \\
\end{array}$ \\
\hline \multirow{2}{*}{ Salmonella } & $\begin{array}{l}\text { S. enterica ser. } \\
\text { Enteritidis }\end{array}$ & 98.60 & 9 & $\begin{array}{c}0 \\
(0 \%)\end{array}$ & $\begin{array}{c}3 \\
(33.33 \%)\end{array}$ & $\begin{array}{c}3 \\
(33.33 \%)\end{array}$ & $\begin{array}{c}0 \\
(0 \%)\end{array}$ & $\begin{array}{c}0 \\
(0 \%)\end{array}$ & $\begin{array}{c}3 \\
(33.33 \%)\end{array}$ \\
\hline & Salmonella sp. & 99.10 & 15 & $\begin{array}{c}2 \\
(13.33 \%) \\
\end{array}$ & $\begin{array}{c}0 \\
(0 \%) \\
\end{array}$ & $\begin{array}{c}4 \\
(26.66 \%) \\
\end{array}$ & $\begin{array}{c}3 \\
(20.00 \%) \\
\end{array}$ & $\begin{array}{c}2 \\
(13.33 \%) \\
\end{array}$ & $\begin{array}{c}4 \\
(26.66 \%) \\
\end{array}$ \\
\hline \multirow{3}{*}{ Staphylococcus } & $\begin{array}{c}\text { Staphylococcus } \\
\text { aureus }\end{array}$ & 98.60 & 18 & $\begin{array}{c}2 \\
(11.11 \%)\end{array}$ & $\begin{array}{c}4 \\
(22.22 \%)\end{array}$ & $\begin{array}{c}3 \\
(16.66 \%)\end{array}$ & $\begin{array}{c}5 \\
(27.77 \%)\end{array}$ & $1(5.55 \%)$ & $\begin{array}{c}3 \\
(16.66 \%)\end{array}$ \\
\hline & $\begin{array}{l}\text { Staphylococcus } \\
\text { xylosus }\end{array}$ & 100.00 & 12 & $\begin{array}{c}0 \\
(0 \%)\end{array}$ & $\begin{array}{c}0 \\
(0 \%)\end{array}$ & $\begin{array}{c}8 \\
(66.66 \%)\end{array}$ & $\begin{array}{c}0 \\
(0 \%)\end{array}$ & $\begin{array}{c}0 \\
(0 \%)\end{array}$ & $\begin{array}{c}4 \\
(33.33 \%)\end{array}$ \\
\hline & $\begin{array}{c}\text { Staphylococcus } \\
\text { epidermis }\end{array}$ & 98.30 & 8 & $\begin{array}{c}0 \\
(0 \%)\end{array}$ & $\begin{array}{c}0 \\
(0 \%) \\
\end{array}$ & $\begin{array}{c}2 \\
(25.00 \%) \\
\end{array}$ & $\begin{array}{c}4 \\
(50.00 \%) \\
\end{array}$ & $\begin{array}{c}0 \\
(0 \%) \\
\end{array}$ & $\begin{array}{c}2 \\
(25.00 \%) \\
\end{array}$ \\
\hline \multirow{2}{*}{ Candida } & Candida albicans & 98.60 & 5 & $\begin{array}{c}0 \\
(0 \%)\end{array}$ & $\begin{array}{c}0 \\
(0 \%)\end{array}$ & $\begin{array}{c}2 \\
(40.00 \%)\end{array}$ & $\begin{array}{c}1 \\
(20.00 \%)\end{array}$ & $\begin{array}{c}0 \\
(0 \%)\end{array}$ & $\begin{array}{c}2 \\
(40.00 \%)\end{array}$ \\
\hline & Candida sp. & 98.30 & 14 & $\begin{array}{c}3 \\
(21.42 \%)\end{array}$ & $\begin{array}{c}2 \\
(14.28 \%)\end{array}$ & $\begin{array}{c}1 \\
(7.14 \%)\end{array}$ & $\begin{array}{c}3 \\
(21.42 \%)\end{array}$ & $\begin{array}{c}4 \\
(28.57 \%)\end{array}$ & $\begin{array}{c}1 \\
(7.14 \%)\end{array}$ \\
\hline Total & & & 151 & $\begin{array}{c}23 \\
(15.23 \%)\end{array}$ & $\begin{array}{c}19 \\
(12.58 \%)\end{array}$ & $\begin{array}{c}39 \\
(25.82 \%)\end{array}$ & $\begin{array}{c}27 \\
(17.88 \%)\end{array}$ & $\begin{array}{c}12 \\
(7.94 \%)\end{array}$ & $\begin{array}{c}31 \\
(20.52 \%)\end{array}$ \\
\hline
\end{tabular}

ID = identification percentages of the strains from API data; ser. = serovar; PM = "Petit Marché"; GM = "Grand Marché"; MD = "Dang market"; CC = "Centre Commercial"; $\mathrm{MBG}=$ "Bamnyanga market"; $\mathrm{MBT}$ = "Bantail market."

of $E$. coli at proportions ranging from a market to another. They also highlighted that some strains of E. coli isolated from fresh beef were identified as Enterohemorrhagic E. coli (E. coli O157: H7). Giving that some strains of E. coli such as Enterohemorrhagic E. coli (EHEC) are recognized as foodborne pathogens associated with several outbreaks of diseases [44], its presence in fresh beef as observed in this study is worrisome. Molecular identification of the strains isolated is required in order to bring more information about their pathogenicity.

The main reservoir of zoonotic Salmonella is food from animal origin, and the main sources of infections incriminated Salmonella in industrialized and developing countries are animal-derived products, notably fresh meat products [45]. In this study, 24 strains of Salmonella were isolated among which there were $37.50 \%$ of S. enterica serovar Enteritidis and $62.50 \%$ of Salmonella sp. (Table 2). Regarding S. enterica serovar Enteritidis, it was found only in sites MD, MBG, and PM at the proportion of $33.33 \%$. Salmonella sp. was absent in the site MD and present in the other sites. Sites MBG and PM rank first with 26.66\% each. Ukut et al. [14] also identified Salmonella spp. in fresh beef sold in Calabar market, Nigeria. In another study conducted by Obeng et al. [39], Salmonella spp. were isolated and identified in fresh meat sold in Tolon and Kumbungu districts of the Northern Region of Ghana.
For yeasts belonging to the genus Candida, Table 2 shows that 19 strains were isolated and identified as the species $C$. albicans (5 strains) and Candida sp. (14 strains). Strains of $C$. albicans were found only in sites MBG, MBT, and PM at proportions of 40,20, and 40\%, respectively. Strains of Candida sp. were identified in fresh beef samples collected from the different sites and the site GM ranks first with $28.57 \%$ of strains. The results of this study are in accordance with those reported by Comi and Cantoni [46] who showed that strains of Candida spp. are dominant yeasts of fresh beef.

In order to visualize the association between the microbial species identified in this study and the sampling sites, a principal component analysis was carried out. Figure 1 presents the distribution of microbial species isolated from fresh beef and sampling sites on the axis system $\mathrm{F} 1 \times \mathrm{F} 2$. As seen in Figure 1, three main groups were formed. The first group shows that the strains belonging to the species C. albicans, Salmonella sp., $P$. aeruginosa, $P$. putida, S. xylosus, and $S$. enteritidis are associated with the sites PM and MBG. The second group shows that the strains belonging to the species Pseudomonas sp., E. coli 1, S. epidermis, and S. aureus are associated with site MBT. Finally, the third group shows that the strains belonging to the species Candida sp. are mainly associated with the sites MD, CC, and GM. This principal component analysis pointed out the specific relationship 
Biplot (axis F1 \& F2 : 83.31\%)

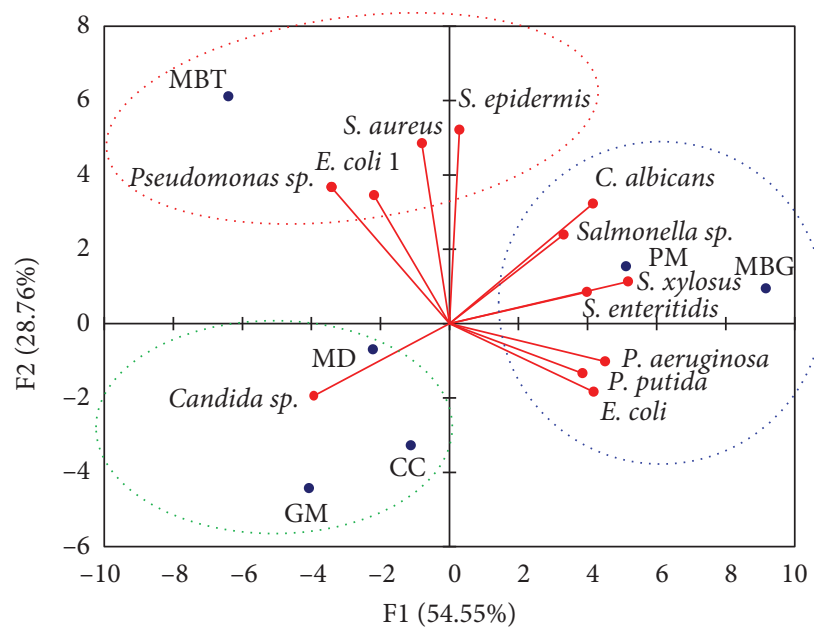

FIGURE 1: Distribution of microbial species isolated from fresh beef and sampling sites on F1 $\times$ F2 axis. PM = "Petit Marché"; GM= "Grand Marché"; $\mathrm{MD}=$ "Dang market"; $\mathrm{CC}=$ "Centre Commercial"; $\mathrm{MBG}=$ "Bamnyanga market"; MBT = "Bantail market."

between the microbial diversity of fresh beef and the sampling sites. It enables to observe associations between the sampling sites and the microbial profile of fresh beef sold in Ngaoundéré. The use of $16 \mathrm{~S}$ rRNA gene sequencing and a high number of meat samples will improve this PCA representation through an increase of the microbial diversity.

3.3. Antiadhesive Activity of Biosurfactant. Food spoilage and disease transmission due to microorganisms attached into surfaces are one of the main problems faced by food industries, particularly in the meat industry. In this study, the antiadhesive property of biosurfactant was tested against some selected bacterial and fungal strains isolated from fresh beef and against some reference cultures. The biosurfactants derived from $L$. paracasei subsp. tolerans N2 inhibited the adhesion of all the tested strains in a dose-dependent manner (Table 3). Biosurfactant was active even at 0.01 against all the tested microorganisms. At that concentration, $33.96 \pm 2.36$ and $27.70 \pm 0.75 \%$ of inhibition were recorded against S. aureus MTCC 1430 and S. aureus STP1. Complete inhibition (100\%) of microbial adhesion was observed against Bacillus sp. BC1, S. aureus STP1, and S. xylosus STP2 at biosurfactant concentration of $10 \mathrm{mg} / \mathrm{mL}$. The least antiadhesive activity $(56.12 \pm 0.16 \%)$ of biosurfactant was noticed against the yeast strain $C$. albicans LV1. This antiadhesive activity of biosurfactants observed in this study could be due to their ability to change the hydrophobicity of the interface between the strain and the surface of the polystyrene plate. Hence, microbial adhesion to the surface will decrease as biosurfactant concentration increases. Sharma and Saharan [21] have explained the antiadhesive activity of biosurfactants of $L$. helveticus by their ability to form a thin film which modifies the wettability of the surface and thus decreases the adhesive properties of microorganisms. The inhibition percentages observed in Table 3 are not different from the values reported by Merghni et al. [22] with biosurfactants from L. casei ATCC 393 LZ9 and L. casei ATCC $393 \mathrm{LBl}$. They noticed inhibition percentages ranging from 68.84 to $84.86 \%$ against $S$. aureus $6538, S$. aureus $9 \mathrm{P}$, and $S$. aureus $29 \mathrm{P}$ at biosurfactant concentration of $12.5 \mathrm{mg} /$ mL. As shown in Table 3, Gram-negative bacteria were more resistant to the antiadhesive activity of biosurfactant. A similar observation was noticed by Sambanthamoorthy et al. [47] with biosurfactants from L. jensenii and L. rhamnosus. This resistance of Gram-negative bacteria could result in their ability to produce, once adhered to surfaces, homoserine lactone acyl (HLA) molecules which increase their resistance to antiadhesive compounds [48].

Besides, the adhesive properties of microorganisms isolated from fresh beef samples as shown in this study suggest that cutting meat surfaces represent an ecological kennel of continuous contamination of meat. Hence, the antiadhesive activity of biosurfactant from $L$. paracasei subsp. tolerans N2 against these strains shows that these molecules could be useful in the reduction of meat contamination through cutting surfaces.

\section{Conclusion}

This study showed that fresh beef sold in the markets of Ngaoundéré contained both pathogenic and spoilage microorganisms at levels higher than the threshold values recommended by the European Commission. Twelve microbial species colonized these fresh beef: $P$. putida, $P$. aeruginosa, Pseudomonas sp., E. coli 1, E. coli, S. enteritidis, Salmonella sp., S. epidermidis, S. xylosus, S. aureus, C. albicans, and Candida sp. with Pseudomonas sp. as the most abundant strains. The presence of Salmonella in all samples makes no doubt on the safety status of the meat. In the same way, the presence of microorganisms like $P$. putida and $P$. aeruginosa which can lead to a quick spoilage of fresh beef suggests a reduced shelf life of the product. However, identification of these strains through $16 \mathrm{~S}$ rRNA gene analyses needs to be done to confirm their identity. The results 


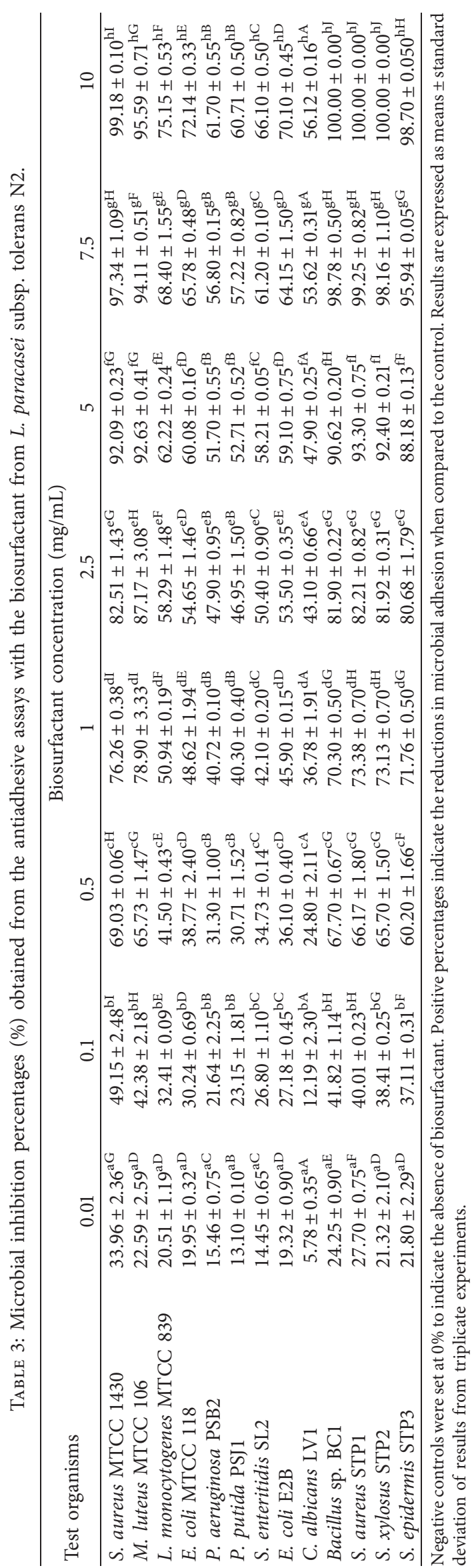


of this study demonstrated the antiadhesive activity of biosurfactant against microbial strains isolated from fresh beef. Efforts made by the Government to improve the microbiological quality of fresh beef should deal not only with the respect of good slaughtering, evisceration, and hygienic practices but also with the cleaning process of surfaces where meat is cut and sold.

\section{Data Availability}

The data used in this study are available from the corresponding author upon request.

\section{Conflicts of Interest}

The authors declare no conflicts of interest.

\section{Acknowledgments}

The authors thank the Director of the National School of Agroindustrial Sciences of the University of Ngaoundéré, Cameroon, and the Department of Microbiology and Fermentation Technology, CSIR-Central Food Technological Research Institute of Mysore, India, for providing necessary facilities for the successful completion of this research work. The authors gratefully acknowledge butchers of the different markets of Ngaoundéré for their kind cooperation during the sampling process.

\section{References}

[1] K. Zerabruk, N. Retta, D. Muleta, and A. T. Tefera, "Assessment of microbiological safety and quality of minced meat and meat contact surfaces in selected butcher shops of Addis Ababa, Ethiopia," Journal of Food Quality, vol. 2019, pp. 1-9, 2019.

[2] A. Holck, L. Axelsson, A. McLeod, T. M. Rode, and E. Heir, "Health and safety considerations of fermented sausages," Journal of Food Quality, vol. 2017, Article ID 9753894, 25 pages, 2017.

[3] G.-J. E. Nychas, P. N. Skandamis, C. C. Tassou, and K. P. Koutsoumanis, "Meat spoilage during distribution," Meat Science, vol. 78, no. 1-2, pp. 77-89, 2008.

[4] G. Thanigaivel and A. S. Anandhan, "Isolation and characterization of microorganisms from raw meat obtained from different market places in and around Chennai," Journal of Pharmaceutical, Chemical and Biological Sciences, vol. 3, no. 2, pp. 295-301, 2015.

[5] Centre for Disease Control (CDC), Multistate Outbreak of Salmonella Enteritidis Infections Linked to Ground Beef, Centre for Disease Control (CDC), Atlanta, GA, USA, 2012.

[6] J. D. Bailly, H. Brugere, and H. Chadron, "Microorganismes et parasites des viandes:les connaître pour les maîtriser de l'eleveur au consommateur CIV," 2012, http://www.civViande.org.

[7] C. Salifou, K. Boko, G. Ahounou et al., "Diversité de la microflore initiale de la viande et sécurité sanitaire des consommateurs," International Journal of Biological and Chemical Sciences, vol. 7, no. 3, pp. 1351-1369, 2013.

[8] S. Datta, A. Akter, I. G. Shah et al., "Microbiological quality assessment of raw meat and meat products, and antibiotic susceptibility of isolated Staphylococcus aureus," Agriculture,
Food and Analytical Bacteriology, vol. 2, no. 3, pp. 187-194, 2012.

[9] E. Abayneh, D. Nolkes, and B. Asrade, "Review on common foodborne pathogens in Ethiopia," African Journal of Microbiology Research, vol. 8, no. 53, pp. 4027-4040, 2014.

[10] T. Kebede, B. Afera, H. Taddele, and A. Bsrat, "Assessment of bacteriological quality of sold meat in the butcher shops of Adigrat, Tigray, Ethiopia," Applied Journal of Hygiene, vol. 3, no. 3, pp. 38-44, 2014.

[11] A. J. Ilboudo, A. Savadogo, S. Samandoulougou, M. Abre, M. Seydi, and A. Traore, "Qualité bactériologique des carcasses de viandes porcines et bovines produites à l'abattoir de Ouagadougou, Burkina Faso," Revue Microbiologie Industrielle, Sanitaire et Environnementale, vol. 10, no. 1, pp. 33-35, 2016.

[12] N. M. Sachindra, P. Z. Sakhare, K. P. Yashoda, and D. Narasimha Rao, "Microbial profile of buffalo sausage during processing and storage," Food Control, vol. 16, no. 1, pp. 31-35, 2005.

[13] B. Siriken, "The microbiological quality of ground beef in Aydin and Afyon Provinces, Turkey," Revue de Médecine Vétérinaire, vol. 155, no. 12, pp. 632-636, 2004.

[14] I. O. E. Ukut, I. O. Okonko, I. S. Ikpoh et al., "Assessment of bacteriological quality of fresh meats sold in Calabar metropolis, Nigeria," Electronic Journal of Environmental, Agricultural and Food Chemistry, vol. 9, no. 1, pp. 89-100, 2010.

[15] A. M. Goja, T. A. A. Ahmed, S. A. M. Saeed, and H. A. Dirar, "Isolation and identification of Staphylococcus spp. in fresh beef," Pakistan Journal of Nutrition, vol. 12, no. 2, pp. 114-120, 2013.

[16] P. Antwi-Agyei and B. K. Maalekuu, "Determination of microbial contamination in meat and fish products sold in the Kumasi metropolis (a case study of Kumasi central market and the Bantama market)," Merit Research Journal of Agricultural Science and Soil, vol. 2, pp. 038-046, 2014.

[17] E. Niyonzima, D. Bora, and M. P. Ongol, “Assessment of beef meat microbial contamination during skinning, dressing, transportation and marketing at a commercial abattoir in Kigali city, Rwanda," Pakistan Journal of Food Sciences, vol. 23, pp. 133-138, 2013.

[18] V. K. Singh, J. Udit, J. K. Yadav, and B. Basanti, “Assessment of bacterial quality of raw meat samples (carabeef, chevon, pork and poultry) from retail meat outlets and local slaughter houses of Agra Region, India," Journal of Foodborne and Zoonotic Diseases, vol. 2, no. 1, pp. 15-18, 2014.

[19] R. B. Afnabi, R. P. Nameni, S. S. Kamdem, J. J. Essia Ngang, and R. B. Alambedji, "Microbial load of beef sold in the traditional slaughterhouse and butcher shops in northern Cameroon," International Journal of Veterinary Science, vol. 4, no. 4, pp. 183-189, 2015.

[20] E. J. Gudiña, E. C. Fernandes, J. A. Teixeira, and L. R. Rodrigues, "Antimicrobial and anti-adhesive activities of cell-bound biosurfactant from Lactobacillus agilis CCUG31450," RSC Advances, vol. 5, no. 110, p. 90960, 2015.

[21] D. Sharma and B. S. Saharan, "Functional characterization of biomedical potential of biosurfactant produced by Lactobacillus helveticus," Biotechnology Reports, vol. 11, pp. 27-35, 2016.

[22] A. Merghni, I. Dallel, E. Noumi et al., "Antioxidant and antiproliferative potential of biosurfactants isolated from Lactobacillus casei and their anti-biofilm effect in oral Staphylococcus aureus strains," Microbial Pathogenesis, vol. 104, pp. 84-89, 2017. 
[23] R. S. Makkar, S. S. Cameotra, and I. M. Banat, "Advances in utilization of renewable substrates for biosurfactant production," AMB Express, vol. 1, no. 5, pp. 1-19, 2011.

[24] International Organization for Standardization (ISO) 17604, Microbiology of the Food Chain-Carcass Sampling for Microbiological Analysis, ISO, Geneva, Switzerland, 2015.

[25] T. H. Mouafo, A. Mbawala, R. Ndjouenkeu, R. Ndjouenkeu, and D. Somashekar, "Application of response surface methodology to improve the production of antimicrobial biosurfactants by Lactobacillus paracasei Subsp," BioMed Research International, vol. 2018, no. 48, pp. 1-15, 2018.

[26] International Organization for Standardization 6887-2, Microbiology of the Food Chain-Preparation of Test Samples, Initial Suspension and Decimal Dilutions for Microbiological Examination-Part 2: Specific Rules for the Preparation of Meat and Meat Products, ISO, Geneva, Switzerland, 2017.

[27] International Organization for Standardization (ISO) 4833-1, Microbiology of the Food Chain-Horizontal Method for the Enumeration of Microorganisms-Part 1: Colony Count at $30^{\circ} \mathrm{C}$ by the Pour Plate Technique, 2013.

[28] International Organization for Standardization (ISO) 4832, Microbiology of Food and Animal Feeding Stuffs-Horizontal Method for the Enumeration of Coliforms-Colony-count Technique, ISO, Geneva, Switzerland, 2006.

[29] International Organization for Standardization (ISO) 215282, Microbiology of the Food Chain-Horizontal Method for the Detection and Enumeration of Enterobacteriaceae-Part 2: Colony-count Technique, ISO, Geneva, Switzerland, 2017.

[30] International Organization for Standardization (ISO) 6888-2, Microbiology of Food and Animal Feeding Stuffs-Horizontal Method for the Enumeration of Coagulase-Positive Staphylococci (Staphylococcus aureus and Other Species)_Part 2: Technique Using Rabbit Plasma Fibrinogen Agar Medium, ISO, Geneva, Switzerland, 1999.

[31] International Organization for Standardization (ISO) 7932, Microbiology of Food and Animal Feeding Stuffs-Horizontal Method for the Enumeration of Presumptive Bacillus Cereus-Colony-count Technique at $30^{\circ} \mathrm{C}$, ISO, Geneva, Switzerland, 2004.

[32] International Organization for Standardization (ISO) 13720, Meat and Meat Products-Enumeration of Presumptive Pseudomonas Spp., ISO, Geneva, Switzerland, 2010.

[33] International Organization for Standardization (ISO) 215271, Microbiology of Food and Animal Feeding Stuffs-Horizontal Method for the Enumeration of Yeasts and Moulds-Part 1: Colony Count Technique in Products with Water Activity Greater than 0,95, ISO, Geneva, Switzerland, 2008.

[34] International Organization for Standardization (ISO) 6579-1, Microbiology of the Food Chain-Horizontal Method for the Detection, Enumeration and Serotyping of Salmonella-Part 1: Detection of Salmonella Spp., ISO, Geneva, Switzerland, 2017.

[35] International Organization for Standardization (ISO) 7937, Microbiology of Food and Animal Feeding Stuff-Horizontal Method for the Enumeration of Clostridium Perfringens-Colony-count Technique, ISO, Geneva, Switzerland, 2004.

[36] D. H. Bergey, J. G. Holt, and N. R. Krieg, Bergey's Manual of Determinative Bacteriology, Lippincott Williams \& Wilkins, East Lansing, MI, USA, 9th edition, 1994.

[37] E. J. Gudiña, V. Rocha, J. A. Teixeira, and L. R. Rodrigues, "Antimicrobial and antiadhesive properties of a biosurfactant isolated from Lactobacillus paracasei ssp. paracasei A20,"
Letters in Applied Microbiology, vol. 50, no. 4, pp. 419-424, 2010.

[38] European Commission Regulation (EC) 2073/2005, "Microbiological criteria for foodstuffs," Official Journal of the European Union, vol. 338, pp. 1-26, 2005.

[39] A. K. Obeng, F. S. Johnson, and S. O. Appenteng, "Microbial quality of fresh meat from retail outlets in Tolon and Kumbungu districts of the northern region of Ghana," International Journal of Science and Technology, vol. 2, no. 6, pp. 423-428, 2013.

[40] F. E. Emele, W. Pasculle, R. H. Glew, and N. Mbrey, "Incidence and prevalence of Aeromonas hydrophila in meat sold in Enugu main market," Nigerian Journal Microbiology, vol. 10, pp. 77-80, 1995.

[41] K. Koutsoumanis, A. Stamatiou, P. Skandamis, and G.-J. E. Nychas, "Development of a microbial model for the combined effect of temperature and $\mathrm{pH}$ on spoilage of ground meat, and validation of the model under dynamic temperature conditions," Applied and Environmental Microbiology, vol. 72, no. 1, pp. 124-134, 2006.

[42] K. B. Ronoh, "Determination of bacteriological quality of fresh beef post-harvesting in Nyagacho Slum," Master thesis, School of Pure and Applied Sciences of Kenyatta University, Kericho, Kenya, 2013.

[43] E. Balcha, K. Ashwani, and T. Habtamu, "Evaluation of safety of beef sold in and around mekelle with special reference to enterohaemorrhagic Escherichia coli O157: H7," Global Veterinaria, vol. 12, no. 4, pp. 569-572, 2014.

[44] H. Karch, P. I. Tarr, and M. Bielaszewska, "Enterohaemorrhagic Escherichia coli in human medicine," International Journal of Medical Microbiology, vol. 295, no. 6-7, pp. 405-418, 2005.

[45] M. Helms, S. Ethelberg, and K. Mølbak, "International Salmonella typhimurium DT104 infections, 1992-2001," Emerging Infectious Diseases, vol. 11, no. 6, pp. 859-867, 2005.

[46] G. Comi and C. Cantoni, "Lieviti e carni," Industrie Alimentari, vol. 24, pp. 683-687, 1985.

[47] K. Sambanthamoorthy, X. Feng, R. Patel, S. Patel, and C. Paranavitana, "Antimicrobial and antibiofilm potential of biosurfactants isolated from Lactobacilli against multi-drugresistant pathogens," BMC Microbiology, vol. 14, no. 1, pp. 1-9, 2014.

[48] P. Biswa and M. Doble, "Production of acylated homoserine lactone by gram-positive bacteria isolated from marine water," FEMS Microbiology Letters, vol. 343, no. 1, pp. 34-41, 2013. 